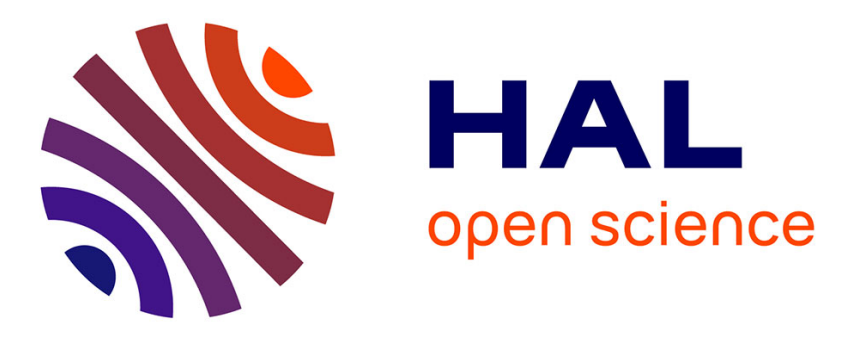

\title{
Experimental investigation of turbulent natural convection in a vertical water channel with symmetric heating: Flow and heat transfer
}

Christophe Daverat, Hervé Pabiou, Christophe Menezo, Hassan Bouia, Shihe Xin

\section{To cite this version:}

Christophe Daverat, Hervé Pabiou, Christophe Menezo, Hassan Bouia, Shihe Xin. Experimental investigation of turbulent natural convection in a vertical water channel with symmetric heating: Flow and heat transfer. Experimental Thermal and Fluid Science, 2013, 44, pp.182-193. 10.1016/j.expthermflusci.2012.05.018 . hal-00868541

\section{HAL Id: hal-00868541 https://hal.science/hal-00868541}

Submitted on 17 Jan 2014

HAL is a multi-disciplinary open access archive for the deposit and dissemination of scientific research documents, whether they are published or not. The documents may come from teaching and research institutions in France or abroad, or from public or private research centers.
L'archive ouverte pluridisciplinaire HAL, est destinée au dépôt et à la diffusion de documents scientifiques de niveau recherche, publiés ou non, émanant des établissements d'enseignement et de recherche français ou étrangers, des laboratoires publics ou privés. 


\title{
Experimental investigation of turbulent natural convection in a vertical water channel with symmetric heating: flow and heat transfer
}

\author{
C. Daverat ${ }^{\mathrm{a}, \mathrm{b}, *}$, H. Pabiou ${ }^{\mathrm{c}}$, C. Ménézo ${ }^{\mathrm{d}}$, H. Bouia ${ }^{\mathrm{e}}$, S. Xin ${ }^{\mathrm{a}, \mathrm{b}}$ \\ ${ }^{a}$ Université de Lyon, CNRS, France \\ ${ }^{b}$ INSA-Lyon, CETHIL, UMR5008, F-69621, Villeurbanne, France \\ ${ }^{c}$ CNRS, CETHIL, UMR5008, F-69621, Villeurbanne, France \\ ${ }^{d}$ Chaire INSA/EDF, Habitats et Innovations Energétiques, Lyon, France \\ ${ }^{e}$ EDF RED - Département EnerBAT - Avenue des Renardières - Écuelles 77818 Moret-sur-Loing Cedex, France
}

\begin{abstract}
The operating temperature of building integrated photovoltaic cells is a key factor in terms of energy efficiency. In order to cool them by natural convection, they are mounted in a double-skin façade configuration, meaning that they are separated from the building wall by a ventilated air channel. Identifying and analysing the physical phenomena governing the air flow and heat transfer in this vertical channel are therefore essential to improve cell-cooling. This analysis can only be performed by detailed numerical simulations coupled with experimental studies to validate the results. In the present work, an experimental model is developed in order to study the coupling between the flow and heat transfer of a natural convection flow in a vertical channel. An original approach is taken, using water as the working fluid to avoid radiative heat transfer and obtain a pure convective flow. First the experimental set-up, the boundary conditions and instruments used to obtain reference data are described. Then simultaneous temperature and velocity measurements are provided. Finally, an analysis of the mean velocity and fluctuations profiles shows a change of the flow behaviour occuring at a sufficiently high Rayleigh number.
\end{abstract}

Keywords: Natural convection, Water, Vertical channel, LDV or LDA measurements, Isoflux conditions, Experimental, Turbulent heat transfer

\section{Introduction}

Governments are committed to reducing greenhouse gas production in order to combat climatic change. This reduction requires increasing the use of renewable energy to produce electricity. Regarding solar energy, building integrated photovoltaic systems (BIPV: Building Integrated PhotoVoltaics) represent one of the main options chosen for its development. However the electrical yield of a solar cell strongly depends on its operating temperature. Its efficiency decreases by $0.5 \%$ per degree with respect to its maximal value for a mono-crystalline solar cell, the type most commonly used today. That is why good understanding of the system's thermal behaviour is a key element in the prediction of its electrical yield. In order to limit PV cell heating, photovoltaic panels are mounted in a double-skin façade configuration, meaning that they are separated from the building wall by an opened air channel. This induces a natural convection flow via a chimney effect that cools the rear surface of the photovoltaic panels. The front side is exposed to external natural ventilation. Studying this flow is therefore important for

\footnotetext{
${ }^{*}$ Corresponding author. Address: CETHIL UMR5008, Domaine scientifique de la Doua, INSA de LYON, F-69621, Villeurbanne, France. Tel.: +33 478437 398, Fax: +33478438 811

Email addresses: christophe.daverat@insa-lyon.fr (C. Daverat), herve.pabiou@insa-lyon.fr (H. Pabiou),

christophe.menezo@insa-lyon.fr (C. Ménézo),

hassan.bouia@edf.fr (H. Bouia), shihe.xin@insa-lyon.fr (S. Xin)
}

understanding and controlling the system. In 2000, Brinkworth [1] presented an analytical model to estimate flow rate and heat transfer behind photovoltaic panels for an integrated configuration. The gap behind the panel was modeled by an inclined channel and the results were validated using previous studies on vertical channels. In 2006, he published [2] a parametric study intended to establish the optimal gap for photovoltaic doubleskin façades. In the same year, he also presented a numerical and experimental study with Sandberg [3] on the influence of transverse ribs on the flow. Small square ribs were found to enhance heat transfer, although they introduce pressure losses and reduce flow rate. Heat transfer enhancement by obstacles in vertical free convective flows had been studied by Da Silva et al. [4] and Bhowmik and Tou [5], but only for discrete heat sources. Auletta et al. [6] dealt with the addition of adiabatic extensions at the inlet and outlet of a vertical channel to enhance heat transfer, focusing on extension size and spacing. Many studies can be found on the global behaviour of double-skin façade systems with different methods of enhancing global heat transfer and mass flow rate. However good understanding of flow behaviour and its local structure, in particular to determine hot points, requires understanding how flows behave in vertical channels.

Many authors have worked on natural convection in vertical channels or between vertical parallel plates for several other applications. The first was Elenbaas in 1942 [7], who worked on 
natural convection between two $12 \times 12 \mathrm{~cm}^{2}$ isothermal parallel plates (with no sidewalls) for cooling electronic components applications. He underlined that heat transfer is characterised by Nusselt, Grashof and Prandtl numbers (the Rayleigh number being the product of the last two) and presented a correlation giving the Nusselt number as a function of the modified Rayleigh number (the product of the Rayleigh number and the channel aspect ratio). His study covered a slightly modified range of Rayleigh numbers $\left(R a_{\mathrm{b}}^{*}<10^{5}\right.$, see eq.13) and pure conductive flow regimes. The flow was assumed to be $2 \mathrm{D}$ at the channel centre. In 1962, Bodoia and Osterle [8] presented the first numerical simulation on natural convection in a 2D isothermal vertical channel. The results were compared with those of Elenbass [7] and showed quite good agreement except for low Rayleigh numbers. This discrepancy was attributed to side leakage effects in Elenbass's experimental apparatus. Moreover they characterised two asymptotic regimes for laminar convective flows in vertical channels. At low Rayleigh numbers, the flow approached the fully developped laminar free convective flow corresponding to the analytical solution given by Aung [9]. For high Rayleigh numbers it tended towards the free convective flow along a vertical flat plate already described by Sparrow and Greg [10]. Wirtz and Stutzman in 1982 [11] studied natural convection in a vertical channel with symmetric isoflux heating. They defined the different flow regimes as a function of the Grashof number ( $\mathrm{Gr}$ calculated on wall heat flux and channel width, see the nomenclature):

- $0<G r<0.2$ : Fully developped flow (Aung's solution [9]);

- $0.2<G r<1000$ : Developping temperature profiles;

- $1000<G r$ : Vertical flat plate (Sparrow's solution [10]).

In 1972, Aung et al. [12] presented a coupled numericalexperimental study. Under isothermal conditions at high Rayleigh numbers their experimental results were $10 \%$ lower than the numerical ones. This difference has also been observed between Bodoia's and Osterle's numerical results [8] and Elenbaas' experimental ones [7]. They ascribed the discrepancies to the assumption of a flat velocity profile at the channel inlet. However, the difference could also be attributed to the 2D hypothesis for the numerical simulations. In their 2D simulations in 1981, Dalbert et al. [13] introduced a pressure loss at the channel inlet in order to satisfy the Bernoulli equation between the hydrostatic conditions far from the channel and the channel inlet. Their results agreed better with the vertical flat plate regime than those of previous studies.

In 1980, Sparrow and Bahrami [14] presented an original experimental setup similar to Elenbaas' but using a naphthalene sublimation technique. They used naphthalene walls instead of heated walls and established the analogy between mass transfer via the Sherwood number and heat transfer via the Nusselt number. This technique eliminated the effects of radiation and variable properties. Their results highlighted a $15 \%$ discrepancy with those of Elenbaas for a range of low Rayleigh numbers because Elenbaas worked with high temperatures and used wall temperature to evaluate air thermophysical properties instead of bulk temperature. Moreover, they closed the lateral edges of the channel and confirmed Bodoia's and Osterle's [8] observations on side leakage effects for low Rayleigh values.

Most of these initial studies focused on describing the global thermal behaviour of the channel through correlations between Nusselt and Rayleigh numbers. In 1984, Bar-Cohen and Rohsenow [15] presented the first review of this correlation, by distinguishing four cases: symmetrical or asymmetrical heating with isoflux or isothermal conditions. While most existing correlations had been formulated for fully developed flows or single flat plate flows in the form $N u_{\mathrm{b}}=C_{1} R a_{\mathrm{b}}^{* C_{2}}$, Bar-Cohen and Rohsenow used a method developed by Churchill and Usagi [16] to propose one correlation for each case which links the two asymptotic regimes.

In 2004, Olsson [17] presented a similar study. He worked on the different existing correlations, including those of BarCohen and Rohsenow, and compared them with experimental results. Finaly he proposed some corrected correlations that are valid for a wide range of Rayleigh numbers. In 1989, Webb and Hill [18] studied the laminar convective flow in an experimental asymmetrically heated vertical channel. They worked on isoflux heating with a modified Rayleigh number (see eq. 13) changing from 500 to $10^{7}$. Their temperature measurements performed in horizontal direction on the heated wall showed variations of $\pm 1.5 \%$, and the flow was assumed to be $2 \mathrm{D}$. They studied correlations for local, average and higher channel Nusselt numbers and compared them to previous works ([9], [10] and [11]). Their correlations were calculated for pure convective flow and the radiation losses were estimated and substracted from the heat input. They found that constants $C_{1}$ and $C_{2}$ were strongly dependent on modified Rayleigh numbers below $R a_{\mathrm{b}}^{*} \sim 10^{5}$ but that they were independent for higher Rayleigh numbers. Good agreement was seen between their results for high Rayleigh numbers and the flat plate solution of Sparrow and Gregg [10]. However, in the log-log diagram the slope of their correlation was found to be $11 \%$ higher than the analytical one. They explained this difference by the uncertainty on correction for radiation and conduction losses and the variation of the thermophysical properties with temperature.

The papers listed above dealt with laminar free convection, but in BIPV applications flows are mainly turbulent. The first authors to study turbulent free convective flow in a vertical channel were Borgers and Akbari in 1984 [19]. They simulated an isothermally heated 2D channel and used former studies on turbulent vertical flat plate flows to develop a code capable of modeling the transition from laminar to turbulent flow. They gave correlations to predict flow rate and heat transfer in turbulent flows. The first experimental study on turbulent flows was developed by Miyamoto et al. in 1986 [20]. They worked on a $5 \mathrm{~m}$ high and $50-200 \mathrm{~mm}$ wide channel asymmetrically heated under isoflux conditions. They focused on the transition from laminar to turbulent regime via velocity and temperature profiles. The flow was seen to be fully turbulent up to $4 \mathrm{~m}$ in all the experiments. In 1997, Fedorov et Viskanta [21] presented a numerical simulation based on Miyamoto's results. In their simulations radiative heat transfers between surfaces were 
neglected and turbulent intensity at the channel inlet was adjusted based on the location of the transition from laminar to turbulent flow. In 1998, Moshfegh and Sandberg [22] presented a study on turbulent flow behind photovoltaic panels mounted on double-façade configuration. The double-façade was investigated both numerically and experimentally and modeled by an asymmetrically heated (isoflux condition) vertical channel with a horizontal inlet. The numerical simulation was $2 \mathrm{D}$ and radiative heat transfers were taken into account. Experimental and numerical results agreed better for laminar regimes than for turbulent ones. For heat fluxes higher than $200 \mathrm{~W} . \mathrm{m}^{-2}$, around $30 \%$ was transmitted to the insulated wall via radiation and dissipated by it.

Cheng and Müller [23] studied both numerically and experimentaly turbulent free convective flows in an asymmetrically heated channel. The two main points of interest in this paper were that it took into account radiative heat transfer and modeled 3D flows. Two different emmissivity values (0.4 and 0.9$)$ were tested on experimental walls and radiative heat transfers were modeled. With an emissivity of 0.9 , radiative heat transfer participates in nearly $55 \%$ of the total heat transfer, whereas for an emmissivity of 0.4 its participation is around $38 \%$. The deviation between numerical and experimental results was less than $10 \%$. Finally a correlation including two terms for convective and radiative heat transfers was developed. In 2002, Habib et al. [24] presented experimental results on turbulent natural convection flows in vertical symmetrically and asymmetrically isothermaly heated channels. Velocity measurements were performed using an LDV system and they provided detailed profiles of mean velocity, rms, flatness and skewness factors in the channel. Moreover, they observed reversed flows at the centre of the channel outlet for symmetrical heating. In 2006, they continued their study ([25], [26]) with PIV measurements and with numerical simulation. The numerical results were obtained for isoflux and isothermal heating. Simulations were performed for 2D flows because the measurements performed in 3 different sections were very similar. However, the lateral edges of the experimental channel were not closed (as was Elenbaas channel), and the 3D investigation was performed in the central part over $60 \%$ of the channel's depth. Moreover, radiative heat transfers were neglected and the authors focused only on correlations for Reynolds and Nusselt numbers.

Giroux-Julien et al. [27] demonstrated a new approach to enhance heat transfer in vertical channel. An original experimental apparatus was developped to study natural convective flow in vertical channels with non uniform isoflux heating. Periodical alternative heating was investigated and they showed that it increased the heat transfer efficiency and could reduce wall temperature from 10 to $15 \%$ compared to uniform heating. Moreover, discrepancies of around 15 to $30 \%$ were observed between experimental and numerical results, and they attributed them to radiation and conduction losses at the channel entrance and outlet.

In 2009, Zamora and Kaiser [28] carried out a numerical study on an asymmetrically heated $2 \mathrm{D}$ vertical channel. They covered a large range of configurations with isoflux and isothermal conditions, laminar and turbulent regimes and Rayleigh numbers (see eq. 13) ranging from $10^{5}$ to $10^{15}$. They were interested by optimising the flow rate and heat transfer and highlighted that neither can be optimized together and that it is necessary to define a compromise. However radiative heat transfer was neglected in their simulations.

This short review shows that the problem of free convection in vertical channels has been subjected to intensive investigation for decades. Nonetheless, two things are clear:

- there is a lack of experimental data, especially for uniform heat flux heating and for turbulent flows ([23], [24] [29]);

- the radiative part of heat transfer is still not completly known and is neglected in many numerical simulations.

Also, 3D flow behaviour has been given very little attention in both numerical and experimental studies, and temperature and velocity fluctuations have been practically overlooked.

In order to answer these problems, a new experimental setup has been developed to study natural convection flow in a vertical water-filled channel.

The experiment's originality stems from the use of water as a working fluid in order to eliminate radiative heat transfer. This set-up has been designed similarly to a vertical air channel [27] in order to reach turbulent regime flows under isoflux conditions. Moreover, the similarity could be used to analyse the role of the radiative heat transfer. Free convective flow in a vertical channel using water has been given little attention. Sparrow et al. ([30] and [31]) were the first to study this configuration. They presented a numerical and experimental investigation in laminar regime and velocity was not measured but only visualized with the thymol blue method. In 2005, Bhowmik et al. ([32] and [5]) worked on water in a vertical channel but with discrete heat sources (applied to the cooling of electronic chips).

In this paper the experimental set-up is first described and the boundary conditions (at the wall and outside of the channel) are characterised. Then, the mean velocity and temperature profiles in the channel (water and walls) are shown. Finally, an analysis of the fluctuations in relation with the mean vertical velocity profiles show a change of the flow regime occuring at a sufficiently high Rayleigh number.

\section{Experimental apparatus}

This part describes the experimental apparatus created for studying natural convection in a vertical water channel.

\subsection{Design}

The experimental setup is shown in figures 1 and 2 . It is divided into three parts: a glass water tank and two waterproof boxes fixed on two supporting systems. The vertical channel (65 cm high and $23.5 \mathrm{~cm}$ deep) is opened at its top and its bottom and is delimited by the two boxes in the $y$ direction and by the glass tank in the $z$ direction.

The tank is built with double glazed glass panes, its height is $1.5 \mathrm{~m}$ and its internal section is $60 \times 23.5 \mathrm{~cm}^{2}$, it is open at its 


\begin{tabular}{|c|c|c|c|}
\hline \multicolumn{4}{|c|}{ Nomenclature } \\
\hline$b$ & channel width $(\mathrm{m})$ & $x, y, z$ & coordinate system $(\mathrm{m})$ \\
\hline$c_{\mathrm{p}}$ & specific heat capacity $\left(\mathrm{J} \cdot \mathrm{kg}^{-1} \cdot \mathrm{K}^{-1}\right)$ & $y^{\prime}$ & dimensionless transverse position (eq. 1b) \\
\hline$D$ & 3D corrective coefficient, $\frac{1}{l} \int_{0}^{l} f_{\mathrm{c}}(x, z) \cdot d z$ & & \\
\hline$f_{\mathrm{c}}$ & $\begin{array}{l}\text { 3D corrective function } \\
\text { gravitational acceleration }\left(\mathrm{m} \mathrm{s}^{-2}\right)\end{array}$ & Greek symbols & thermal diffusivity $\left(\mathrm{m}^{2} \mathrm{~s}^{-1}\right)$ \\
\hline$G r$ & Grashof number, $\frac{g \beta \dot{q}_{w} b^{4}}{l^{2}}$ & $\beta$ & volumetric expansion coefficient $\left(\mathrm{K}^{-1}\right)$ \\
\hline $\begin{array}{l}H \\
k\end{array}$ & height of the heated surface $(\mathrm{m})$ & $\Delta \dot{M}$ & $\begin{array}{l}\text { mass flow rate difference between outlet } \\
\text { and inlet }\left(\mathrm{kg} \mathrm{s}^{-1}\right)\end{array}$ \\
\hline $\begin{array}{l}l \\
\dot{M}\end{array}$ & $\begin{array}{l}\text { channel depth }(\mathrm{m}) \\
\text { mass flow rate }\left(\mathrm{kg} \cdot \mathrm{s}^{-1}\right)\end{array}$ & $\Delta T$ & $\begin{array}{l}\text { time averaged temperature difference, } \\
\left(T-T_{\text {in }}\right)(\mathrm{K})\end{array}$ \\
\hline$N u_{\mathrm{b}}$ & $\begin{array}{l}\text { Nusselt number based on channel width } \\
\text { (eq. 15) }\end{array}$ & $\Delta T^{*}$ & $\begin{array}{l}\text { instantaneous temperature difference, } \\
\left(T^{*}-T_{\mathrm{in}}^{*}\right)(\mathrm{K})\end{array}$ \\
\hline$\dot{q}_{\mathrm{w}}$ & wall heat flux $\left(\mathrm{W} \cdot \mathrm{m}^{-2}\right)$ & $\Delta T_{\mathrm{H}}$ & time average temperature difference aver- \\
\hline$\dot{Q}_{f}$ & heat rate transported by the mean flow (W) & & aged on the walls, $\frac{1}{H} \int_{0}^{H}\left(T_{\mathrm{w}}-T_{\mathrm{in}}\right) \cdot d x(\mathrm{~K})$ \\
\hline$\dot{Q}_{f}^{\prime}$ & heat rate transported by the fluctuating flow & $\theta$ & dimensionless temperature (eq. 1a) \\
\hline & $(\mathrm{W})$ & $\theta^{\prime}$ & fluctuating part of temperature difference, \\
\hline$R a_{\mathrm{b}}^{*}$ & $\begin{array}{l}\text { modified Rayleigh number based on chan- } \\
\text { nel width (eq. 13) }\end{array}$ & $\mu$ & $\begin{array}{l}\Delta T\left({ }^{\circ} \mathrm{C}\right) \\
\text { dynamic viscosity }\left(\mathrm{Pa}^{-1} \mathrm{~s}^{-1}\right)\end{array}$ \\
\hline $\operatorname{Re}$ & Reynolds number (eq. 14) & $v$ & kinematic viscosity $\left(\mathrm{m}^{2} \cdot \mathrm{s}^{-1}\right)$ \\
\hline$S$ & area of the heated surface $\left(\mathrm{m}^{2}\right)$ & $\rho$ & density $\left(\mathrm{kg} \cdot \mathrm{m}^{-3}\right)$ \\
\hline$t$ & time $(\mathrm{s})$ & $\sigma_{\mathrm{u}}, \sigma_{\mathrm{v}}, \sigma_{\mathrm{T}}$ & standard deviation of velocity components \\
\hline$T$ & time averaged water temperature $\left({ }^{\circ} \mathrm{C}\right)$ & & $u$ and $v$ and temperature, respectively \\
\hline$T^{*}$ & instantaneous temperature $\left({ }^{\circ} \mathrm{C}\right)$ & & $\left(\mathrm{m} \cdot \mathrm{s}^{-1} \mathrm{or}^{\circ} \mathrm{C}\right)$ \\
\hline$u_{\mathrm{b}}$ & $\begin{array}{l}\text { velocity averaged over time and channel } \\
\text { section, } \frac{D}{b} \int_{0}^{b} u \cdot d y\left(\mathrm{~m} \cdot \mathrm{s}^{-1}\right)\end{array}$ & $\tau$ & duration used for time averages (s) \\
\hline$u, v, w$ & $\begin{array}{l}\text { time average velocity components in } x, y \\
\text { and } z \text { directions, respectively }\left(\mathrm{m} \cdot \mathrm{s}^{-1}\right)\end{array}$ & $\begin{array}{l}\text { Subscripts } \\
\text { in }\end{array}$ & value at channel inlet \\
\hline$u^{\prime}, v^{\prime}, w^{\prime}$ & fluctuating parts of velocity components in & out & value at channel outlet \\
\hline$u^{*}, v^{*}, w^{*}$ & $\begin{array}{l}x, y \text { and } z \text { directions, respectively }\left(\mathrm{m} \cdot \mathrm{s}^{-1}\right) \\
\text { instantaneous velocity components in } x, y \\
\text { and } z \text { directions, respectively }\left(\mathrm{m} \cdot \mathrm{s}^{-1}\right)\end{array}$ & w & value at wall \\
\hline
\end{tabular}

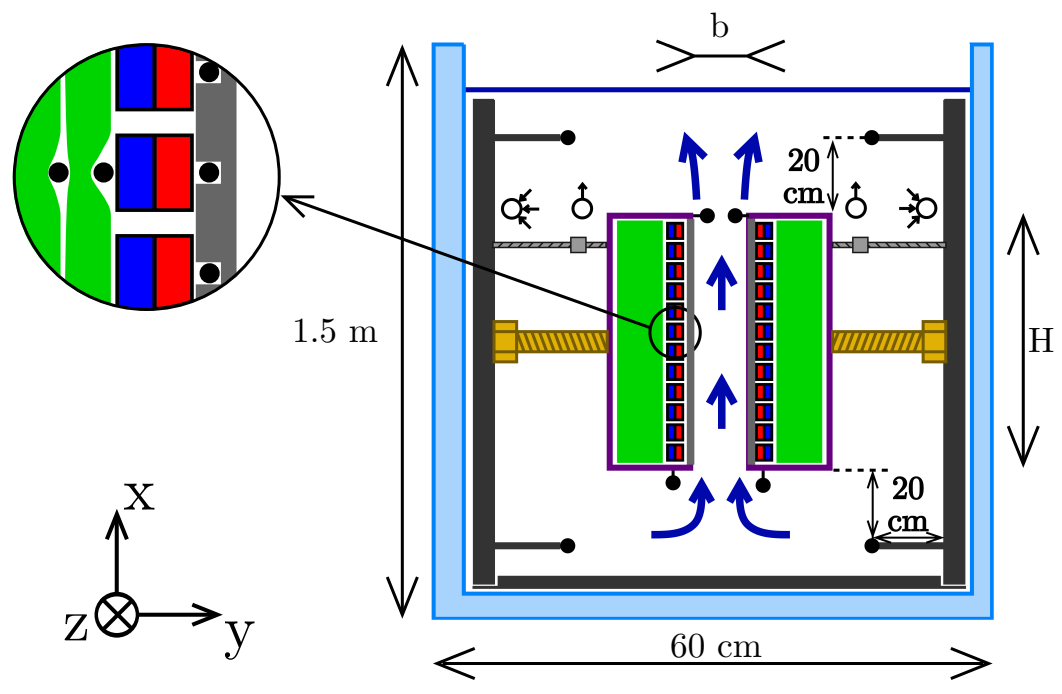

\begin{tabular}{|c|c|}
\hline$\square$ & Double glazing water tank \\
\hline & PVC support \\
\hline DIV & Brass screw system \\
\hline & Waterproof box \\
\hline & Stainless steel plate $(1.5 \mathrm{~mm}$ thick $)$ \\
\hline & Heat flux sensor / Heater \\
\hline & Adiabatic silicone foam \\
\hline$\Delta \nabla$ & Wall adjustment system \\
\hline 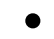 & Thermocouple \\
\hline$\sigma_{k}^{k}$ & Sucking up water \\
\hline$\hat{0}$ & Going back water \\
\hline
\end{tabular}

Figure 1: Cross section in the xOy plane showing the different parts and sensors of the experimental apparatus. The dimension ratios are not represented faithfully in this drawing. 
top and filled with $180 \mathrm{~L}$ of distilled water. The two supporting systems are composed of a brass screw fastening system fixed to the waterproof box on one end and to a PVC board on the other end. The PVC board is $1.5 \mathrm{~cm}$ wide and is reinforced by two stainless steel support angles to increase its rigidity.

The brass screw linking each box to its PVC support allows adjusting the channel gap ( $b$, space between boxes in the $y$ direction) between 0 and $14 \mathrm{~cm}$.

The main techonological difficulty of this experiment stems from the tightness of the boxes. Moreover, the large surface area of the boxes, which also provide the heated walls of the channel, must have a higher thermal conductivity than the other side of the box to avoid heat leaks. Each box is composed of a stainless steel plate (heated wall of the channel) stuck with double coated foam on a polycarbonate frame and closed by a polycarbonate cover fixed by 48 screws.

The heated walls of the channel are $65 \mathrm{~cm}$ high, $23 \mathrm{~cm}$ wide and $1.5 \mathrm{~mm}$ thick. Two types of $1 \mathrm{~mm}$ deep grooves are engraved on the inner faces of the plate: thirteen $21 \mathrm{~cm}$ long grooves parallel to the $z$ axis that mark out twelve areas $5 \mathrm{~cm}$ high, and twelve $2.5 \mathrm{~cm}$ grooves parallel to the $x$ axis in the centre of each area. The diagram of the groove positions is shown in figure 3. The grooves parallel to the $x$ axis are used to insert thermocouples into the plate (see fig. 1). As displayed in figure 1 , twelve $5 \times 20 \mathrm{~cm}^{2}$ electric heaters are placed on each plate in the twelve areas delimited by the horizontal grooves. The latter are intended to avoid thermal conduction in direction $x$ between two heated areas. Therefore, the height of the heated part $(H)$ is only $61.1 \mathrm{~cm}$. As the heaters are not stuck on the plate, effective contact between the heaters and the stainless steel plate is provided by 3 layers of adiabatic silicon foam placed on the heater and compressed when the polycarbonate cover is closed. The channel is .

To adjust the verticality and the parallelism of the heated walls, the top of each waterproof box is linked to its PVC support plate by another screw system (see fig. 1). A Laser Doppler Velocimtetry (LDV) system and a brass pole supporting a micro-thermocouple are mounted on a mobile 2D system to measure the velocity and temperature in the channel. The verticality of the mobile LDV system is set for use as the reference. The verticality and parallelism of the channel walls are then adjusted in relation to the two vertical laser beams fixed on the moving system. The channel gap difference between the inlet and outlet is $0.5 \mathrm{~mm}$ with a mean gap $(b)$ around $45.1 \mathrm{~mm}$, therefore the channel gap precision is in the region of $1 \%$.

\subsection{Thermal Boundary conditions}

The boundary conditions in the channel are isoflux conditions on the heated walls (stainless steel plates) and adiabatic conditions on the lateral walls (glass tank walls). Each stainless steel plate is heated by 12 separate electrical resistances that can each impose a constant heat flux on an $5 \times 20 \mathrm{~cm}^{2}$ area. The 24 heaters are connected in parallel to an Agilent 6675A $2 \mathrm{~kW}$ DC power supply. The voltage is delivered at a stability of \pm 0.02 $\mathrm{V}$. The internal electrical resistance of each heater is adjusted by adding resistance connected in series in order to equalize the heat fluxes entering in the channel.

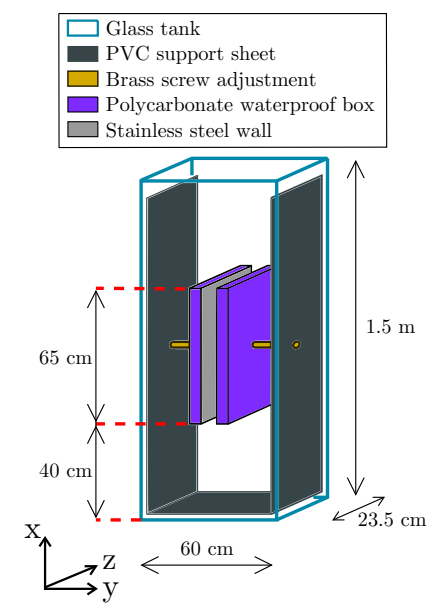

Figure 2: Drawing of the experimental apparatus.

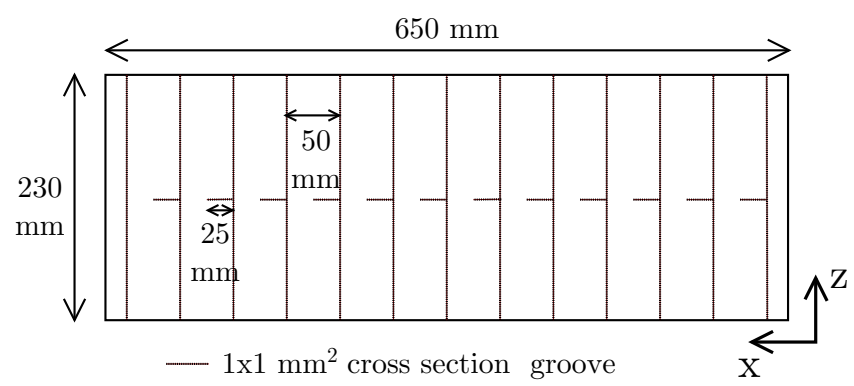

Figure 3: Diagram of the inner face of the heated stainless steel plate with positions of the $1 \times 1 \mathrm{~mm}^{2}$ cross section grooves.

The adiabatic condition on the lateral sides of the channel (parallel to plane $\mathrm{xOy}$ ) is provided by the tank double glazing covered by external insulation of $5 \mathrm{~cm}$ of Styrodur with a thermal conductivity of $0.033 \mathrm{~W} \cdot \mathrm{m}^{-1} \cdot \mathrm{K}^{-1}$. An opening is made in the external insulation to allow LDV measurement in the channel. The bench is placed in a room whose temperature is controlled to within $\pm 2^{\circ} \mathrm{C}$ (see fig. 4).

The water temperature is regulated by an external system composed by a pump, a heat exchanger and a Lauda RP 845 thermoregulated bath with a cooling power of $1.6 \mathrm{~kW}$. The water is pumped at the channel exit level, close to the PVC support plates (sucking up symbols on fig. 1); then it is cooled through the heat exchanger and goes back to the tank at the same level just behind the waterproof boxes (going back symbols on fig. 1). Suction and discharge are ensured through diffusers (drilled PVC tubes) which distribute the flow rate along $z$ direction in order to limit disturbances in the convective flow. The four diffusers ( 2 for suction and 2 for discharge) are positioned symmetrically on both sides of the channel, as shown in figure 1 .

\subsection{Instrumentation}

The experimental setup is fitted with 56 fixed sensors: 24 Captec ultrathin heat fluxmeters and 32 K-type (ChromelAlumel) thermocouples of $120 \mu \mathrm{m}$. The sensors are positioned symmetricaly as shown in figure 1 . They are connected to an Agilent 34980A digital multimeter. 
The heat fluxmeters are located between the heater and the silicon foam (heat loss measurement) to minimize thermal resistance between the heaters, which apply an isoflux condition, and the water in the channel. In this configuration the thermal resistance between the heaters and water is the sum of the stainless steel plate resistance and the contact resistance between the plate and the heater. The heat flux injected by each heater in the channel through the stainless steel plate is obtained from the difference between the input electrical power and the measured heat losses. The heat flux acquisition chain was calibrated in the laboratory using an original apparatus designed for this type of sensor. The calibration used a scale from 0 to $50 \mathrm{~W} \cdot \mathrm{m}^{-2}$ which corresponds to the order of magnitude of the losses measured $(\sim$ $2 \%$ of the heat flux injected in the channel). The heat fluxmeter precision given by the calibration was $1.2 \%$ of the value measured, corresponding to a precision of $0.02 \%$ of the heat flux injected in the channel.

The temperatures in the experimental apparatus were measured using 32 thermocouples positionned as shown in figure 1. 24 thermocouples, embedded in the stainless steel plates at the centre of each heater (see $\$ 2.1$ ), were used to measure the temperatures of the channel walls. The thermocouples were placed in the grooves, $1 \mathrm{~mm}$ deep and $2.5 \mathrm{~cm}$ long, filled with conductive mastic. The latter prevented the thermocouple from moving and avoided additional thermal resistance between the heaters and the stainless steel walls. 4 thermocouples ( 2 per box) were used to estimate the temperatures just behind the central heater and between the first and second foam layers (see fig. 1). The last 8 thermocouples determined the water temperature in the tank, as shown in figure 1. The room temperature and temperature inside the right diffuser are also measured (not shown in figure 1). The thermocouple cold junctions were embedded in two copper rods insulated with hemp; the thermocouple cold junctions of the right part of the experimental setup were separated from those of the left part. The temperature in each rod was measured by a platinium resistive thermal device (Pt100). The temperature measurement chain (Pt100, thermocouples, and multifunction switch) was calibrated in the laboratory using our own system. The resistance thermometer was calibrated between 10 and $30^{\circ} \mathrm{C}$ and the thermocouples between 10 and $70^{\circ} \mathrm{C}$. The precision of the temperature of the platinium resistance thermometers (which measure cold junction temperatures) was estimated to within $\pm 0.02^{\circ} \mathrm{C}$; thermocouple precision was $\pm 0.05^{\circ} \mathrm{C}$.

Investigations on temperature and velocity in the channel were peformed with an LDV system and a $25 \mu \mathrm{m}$ K-type thermocouple combined with a two directional moving system. Thus velocity and temperature could be measured on the tank over $1.5 \mathrm{~m}$ in the $x$ direction and $20 \mathrm{~cm}$ in the $y$ direction with an accuracy within $10 \mu \mathrm{m}$. To avoid interaction between the thermocouple and laser beams, the micro-thermocouple was located $1 \mathrm{~mm}$ above the LDV measurement volume by a brass mount $3 \mathrm{~mm}$ in diameter.

The velocity measurements were carried out using a commercial LDV (TSI Inc.) together with an argon ion laser. This system gives velocity components in $x$ and $y$ directions. The seeding materials used were $20 \mu$ m polyamide particles with

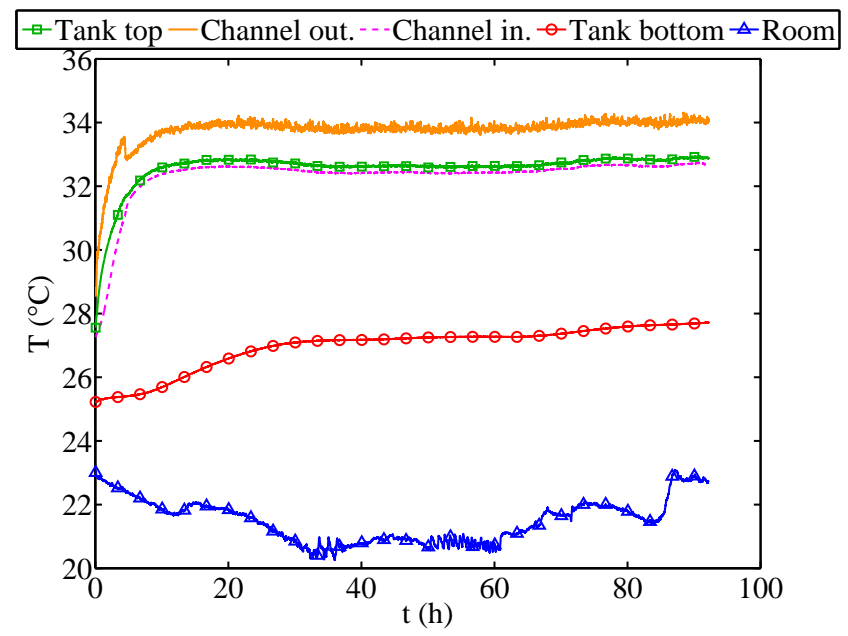

Figure 4: Temperature evolutions in the left part of the tank and in the room during experiment 4 (see table 1). The location of the thermocouple in the tank is given in fig. 1. «Out» and «in» stand for outlet and inlet.

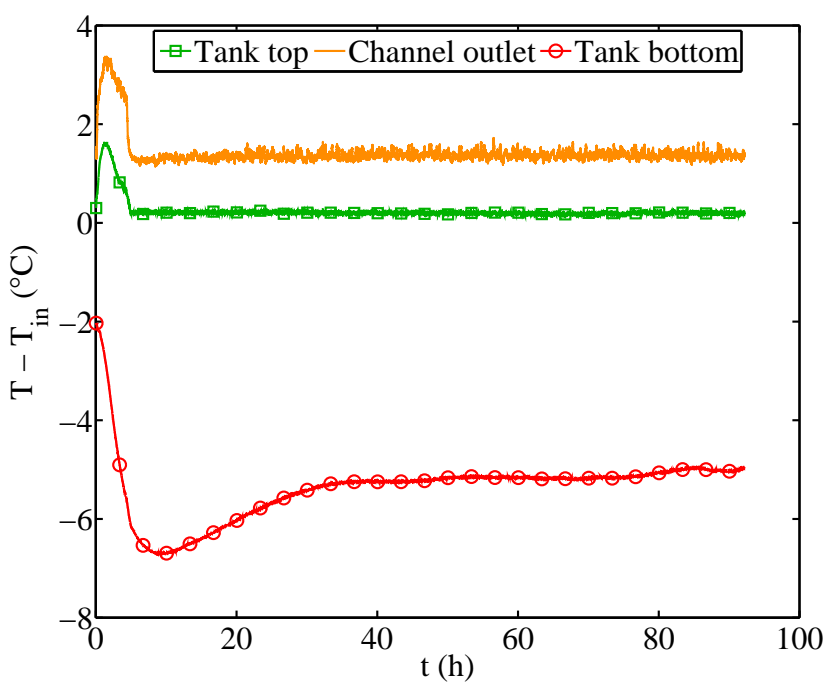

Figure 5: Difference between temperature in the tank and channel inlet temperature during the experiment 4 (see table 1 ).

a density of $1030 \mathrm{~kg} \cdot \mathrm{m}^{-3}$. The sampling rates were $3-15 \mathrm{~Hz}$, which is more than 10 times higher than the cutoff frequency in the velocity power spectrum $(\sim 0.2 \mathrm{~Hz})$. This rate depended on the location in the channel and it was lower close to the wall where there were few particules.

The micro-thermocouple was connected to a Keithley 2701 data acquisition system allowing a data rate of $500 \mathrm{~Hz}$. Its cold junction was placed in another copper cylinder insulated from external perturbations with another platinium resistance thermometer. It was calibrated in the same way as the thermocouples described above, with the same precision.

\subsection{Characterisation}

All the velocity and temperature measurements in the channel were performed under steady-state conditions. Figure 4 presents the temperature evolutions at the top and bottom of the 


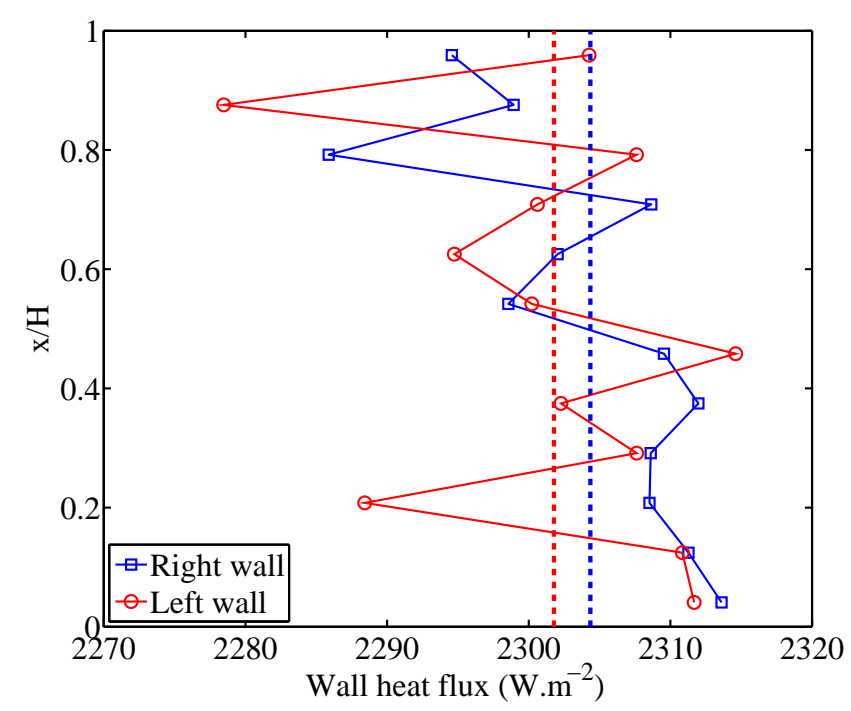

Figure 6: Time average heat flux on channel walls (square: right, circle: left) versus dimensionless channel height during experiment 5 (see table 1). Heat flux is calculated on each heater by heat fluxmeter and power supply measurements. Heat flux averaged over height (dotted line) is $2302 \mathrm{~W} \cdot \mathrm{m}^{-2}$ on the left wall and $2304 \mathrm{~W} . \mathrm{m}^{-2}$ on the right.

tank, at the channel inlet and outlet and in the room (thermocouple positions are shown in fig. 1) during experiment 4 (see table 1). After a sharp evolution in the first hours, temperature at the entry and the exit of the channel remained almost constant. Because the tank bottom was not insulated and stratification occured due to a lack of mixing below the channel, a slow evolution of the tank bottom temperature is seen on figure 4. To determine whether the steady-state is reached or not, figure 5 shows the difference between several temperatures in the tank and the channel inlet temperature during the experiment 4 (see table 1). Although the absolute water temperatures evolved, all temperature differences remained constant within $\pm 0.1^{\circ} \mathrm{C}$ after $40 \mathrm{~h}$ and therefore steady-state could be assumed. For all the experiments, statistically steady-state regime was generally reached after 24-48 hours, depending on the experimental conditions. The homogeneity of the temperature outside the channel was estimated by the temperature difference between the tank top temperature and the inlet temperature. The maximum difference, measured during experiment 5 (see table 1), was $0.5^{\circ} \mathrm{C}$ which allows us to neglect the stratification outside the channel.

The second controlled boundary condition was the uniform isoflux condition on the channel walls. It is presented in figure 6 by plotting the mean wall heat flux on each heater versus the dimensionless channel height during experiment 5 (see table 1). It shows that a uniform isoflux condition is reached with mean variations lower than $1 \%$. On the other hand the maximum instantaneous fluctuations measured are lower than $2 \%$ (not shown in figure 6). Moreover, the difference between the mean heat flux on the left and right walls is lower than $0.01 \%$. Thus uniform symmetrical isoflux condition can be assumed on the channel walls.

\begin{tabular}{|c|c|c|c|c|c|}
\hline \multirow{3}{*}{ Exp. } & Wall & \multicolumn{2}{|c|}{ Temperatures } & \multirow{3}{*}{$\begin{array}{c}\quad R a_{\mathrm{b}}^{*} \\
\text { (see eq. 13) }\end{array}$} & \multirow{3}{*}{$\begin{array}{c}b \\
(\mathrm{~mm})\end{array}$} \\
\hline & heat flux & Inlet & Top tank & & \\
\hline & $\left(\mathrm{W} \cdot \mathrm{m}^{-2}\right)$ & $\left({ }^{\circ} \mathrm{C}\right)$ & $\left({ }^{\circ} \mathrm{C}\right)$ & & \\
\hline 1 & 190 & 22.58 & 22.62 & $1.7110^{6}$ & 45.1 \\
\hline 2 & 382 & 23.45 & 23.48 & $3.5310^{6}$ & 45.1 \\
\hline 3 & 764 & 27.31 & 27.36 & $9.2210^{6}$ & 45.1 \\
\hline 4 & 1147 & 32.56 & 32.60 & $1.7410^{7}$ & 45.1 \\
\hline 5 & 2305 & 36.54 & 36.58 & $4.2610^{7}$ & 45.5 \\
\hline
\end{tabular}

Table 1: Configuration for the five experiments. Wall heat flux is the value averaged over the two walls and over time. Inlet and tank top temperatures are time averaged values. Channel with $b$ is the mean between channel width at inlet and outlet.

\section{Results}

Five experiments were performed with five heat flux conditions. In order to remain within the band of the Boussinesq approximation [33], the water tank temperature was adjusted for each case. The experimental conditions of the 5 experiments are summarized in table 1 , the mean channel width is $45.1 \mathrm{~mm}$ for experiments $1-4$ and $45.5 \mathrm{~mm}$ for experiment 5 .

\subsection{Temperature and heat transfer measurements}

Figure 7 shows temperature difference between the right wall and the inlet along the channel wall for the 5 experiments. Channel wall temperature increases with respect to channel vertical position and with increasing wall heat flux. In the first two experiments (the lowest heat fluxes) the temperature increase appears to be regular, whereas in the three others (highest heat fluxes) a temperature decrease can be seen from the eighth to the tenth heater. This effect is emphasized as the wall heat flux increase. This change in temperature profile is related to a change in flow regime located around the tenth heater as it will be described in this paper.

Figure 8 presents temperature profiles at the half channel outlet for 4 experiments (water temperatures were not measured during experiment 2). Only half profiles are displayed here because the supporting system of the micro-thermocouple does not allow to measure temperature close to the right wall. Mean channel temperature, with regard to inlet temperature, increased at the same time as wall heat flux increased but the mid-channel temperature $(0.2<y / b<0.8)$ remained fairly constant between the inlet and the outlet (except for experiment 5 that shows a slight temperature increase). All the heat transfer took place in the thermal boundary layer. As we measured the wall heat flux, the validity of the temperature measurement close to the wall can be checked.

Figure 9 displays a dimensionless temperature $\theta$ along a half profile at the channel outlet versus a dimensionless transverse position $y^{\prime}$ : 


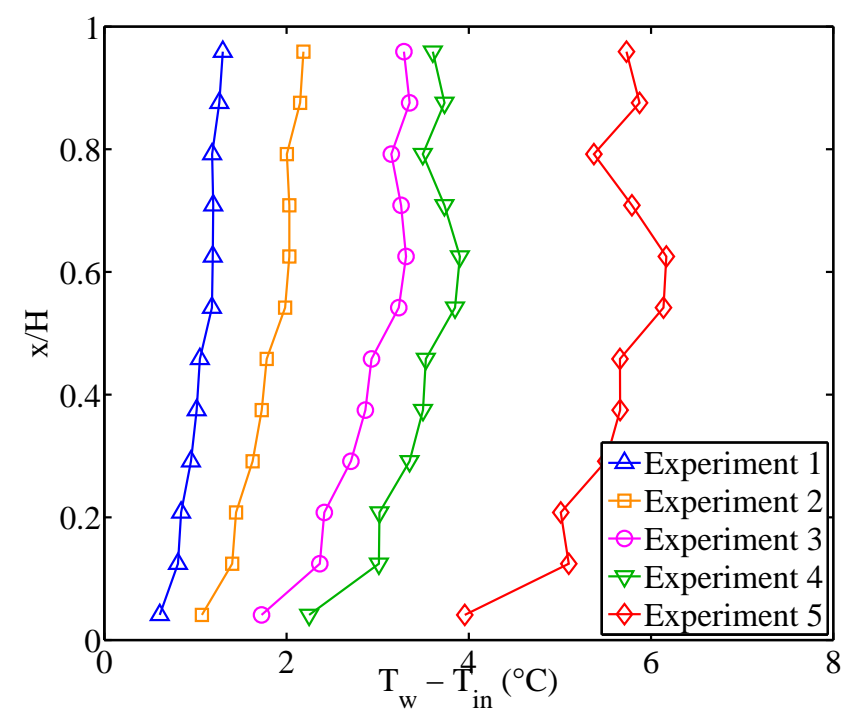

Figure 7: Time averaged temperature differences between the right wall and the inlet versus dimensionless channel height for all the experiments (see table 1).

$$
\begin{aligned}
\theta & =\frac{T-T(y / b=0.5)}{T(y / b=0)-T(y / b=0.5)} \\
y^{\prime} & =\frac{\dot{q} y}{k(T(y / b=0)-T(y / b=0.5))}
\end{aligned}
$$

The temperature gradient at the wall is:

$$
\frac{\partial T}{\partial y}(y=0)=-\frac{\dot{q}}{k}
$$

which can be written:

$$
\frac{\partial \theta}{\partial y^{\prime}}\left(y^{\prime}=0\right)=-1
$$

The slope of the bold black line on figure 9 is minus one. This figure also displays a detailed profile (4') obtained under the same conditions as those of experiment 4 . These profiles show that the wall temperature gradients can be measured with a good accuracy.

\subsection{Velocity measurements}

Figure 10 presents 3 different rolling averages calculated for a vertical velocity measurement during experiment 3 . The instantaneous velocity signal (not shown) exhibits very large fluctuations with a peak to peak amplitude around $\pm 1 \mathrm{~cm} . \mathrm{s}^{-1}$ which is of the order of the mean. The rolling average velocities also show fluctuations, even when calculated for over more than one hour. The choice of measurement duration is a compromise between the time needed to make a profile and the measurement uncertainty. For timing reasons, it was chosen to calculate the mean velocity for a duration of 25-30 min which leads to an error bar on the velocity profiles of $\pm 2 \mathrm{~mm} . \mathrm{s}^{-1}$. Therefore it took around $7 \mathrm{~h}$ to measure a complete velocity profile. Horizontal velocity is not presented here: its mean value is very weak in

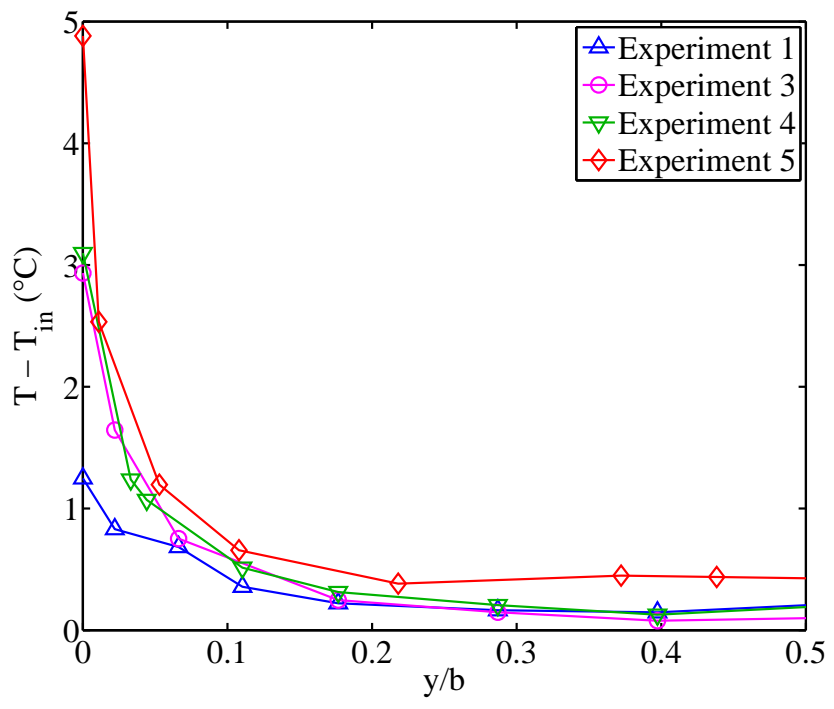

Figure 8: Time averaged (on 25-30 $\mathrm{min}$ ) temperature profile in the half channel mid-plane $(\mathrm{x} / \mathrm{H}=0.96, \mathrm{z} / \mathrm{l}=0.5)$ versus the dimensionless distance from the left wall. The inlet temperature was deducted to compare the different experiments.

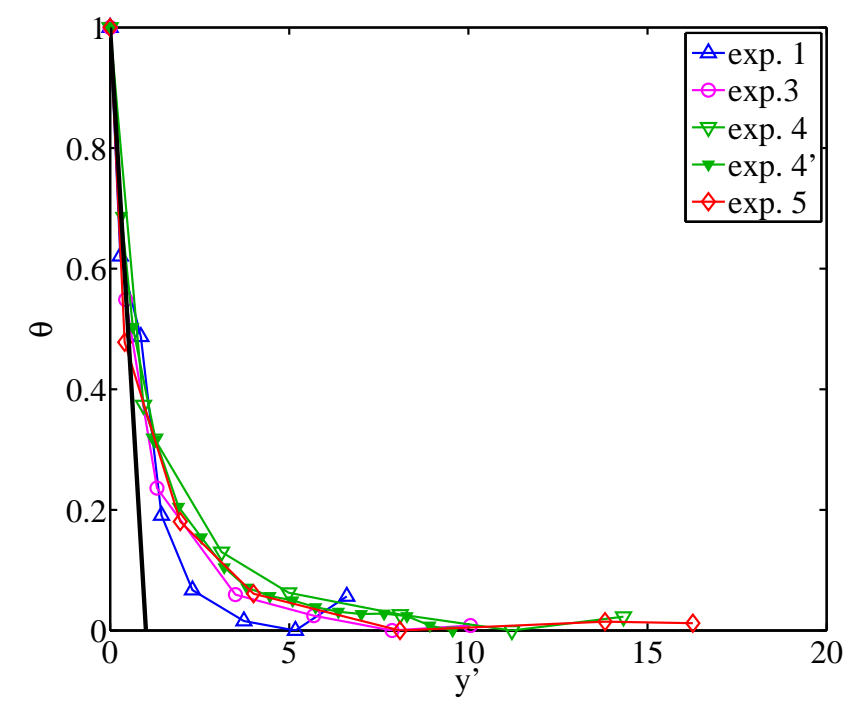

Figure 9: Dimensionless time averaged temperatures in the half channel midplane $(x / H=0.90, z / l=0.5)$ versus the local Nusselt number. The bold black line shows the dimensionless temperature gradient at the wall. The temperatures are averaged over 25-30 min. Experiment 4' displays a more detailed profile obtained under the same conditions as for experiment 4. 


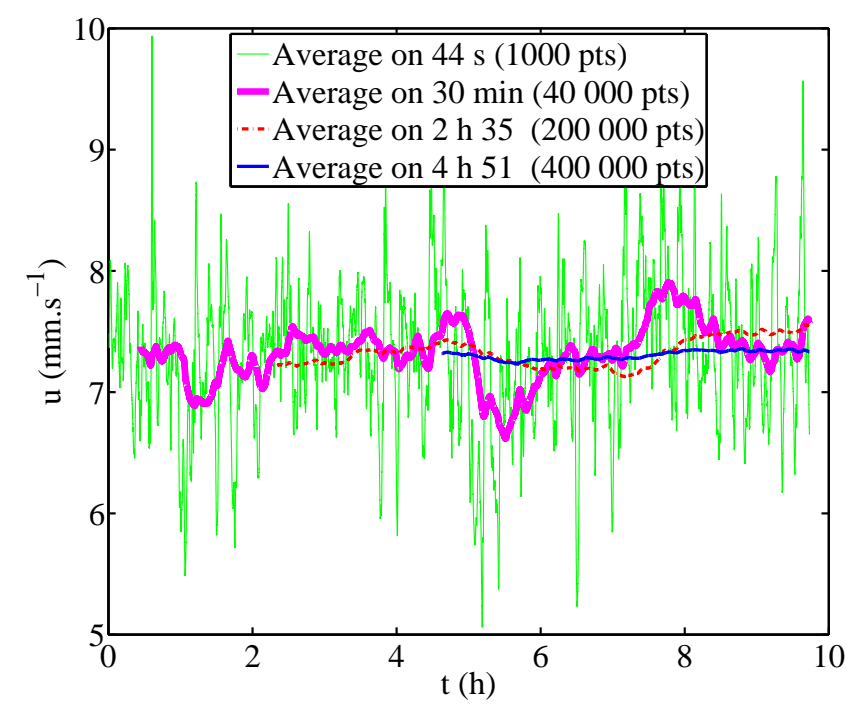

Figure 10: Rolling averages calculated on a vertical velocity measurement during experiment 3 at $x / H=0.90, y / b=0.51$ and $z / l=0.5$.

the centre of the channel and it could not be measured close to the wall because one of the laser beams was impeded by the box.

Figures 11 and 12 show velocity profiles at the channel inlet and outlet in the 5 experiments. A chimney effect can be seen at the channel inlet with fluid rising upwards through the entire channel gap, as in the study by Miyamoto et al. [20]. It can also be seen that the volume flow rate (proportional to the mean velocity in the channel) increases when the wall heat flux increases. The dynamic boundary layers developed along the channel because two velocity peaks appear next to the walls. The higher the wall heat flux is the higher the velocity peaks are. Furthermore, the velocity at the channel centre reaches a plateau as shown in figure 12. It can be seen that for the first three experiments the maximum velocities increase but velocity at the centre remains almost the same; this fact will be analysed below (\$3.5).

\subsection{Mass conservation}

The mass flow rate $\dot{M}$ under the Boussinesq approximation conditions is defined as follow:

$$
\dot{M}(x)=\rho \int_{0}^{l} \int_{0}^{b} u(x, y, z) \cdot d y \cdot d z .
$$

As velocity measurement can not be performed in the whole channel section, principally for time reasons, we assume that:

$$
u(x, y, z)=f_{\mathrm{c}}(x, z) \times u(x, y, z / l=0.5) ;
$$

where $f_{\mathrm{c}}(x, z)$ is a corrective function. Unfortunately, velocity profiles along $z$ were not measured for experiments 1-5 presented here (see table 1). Nevertheless, to estimate the mass flow rate we assume that the function $f_{\mathrm{c}}$ depends weakly on the Rayleigh number $\left(R a_{\mathrm{b}}^{*}\right)$ and we use a new measurement performed at $R a_{\mathrm{b}}^{*}=5.76 .10^{7}$. The corrective function $f_{\mathrm{c}}$ is plotted on figure 13 . One measurement is done at the inlet

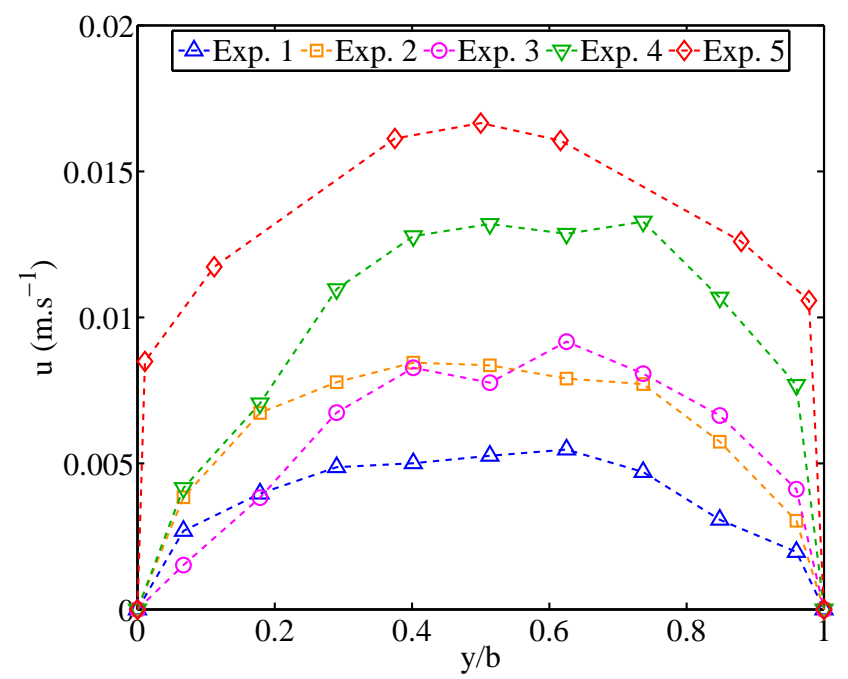

Figure 11: Mean vertical velocity in the channel mid-plane $(z / l=0.5)$ at the inlet $(x / H=0.04)$ versus the dimensionless distance from the left wall. Average velocities are calculated over $25-30 \mathrm{~min}$.

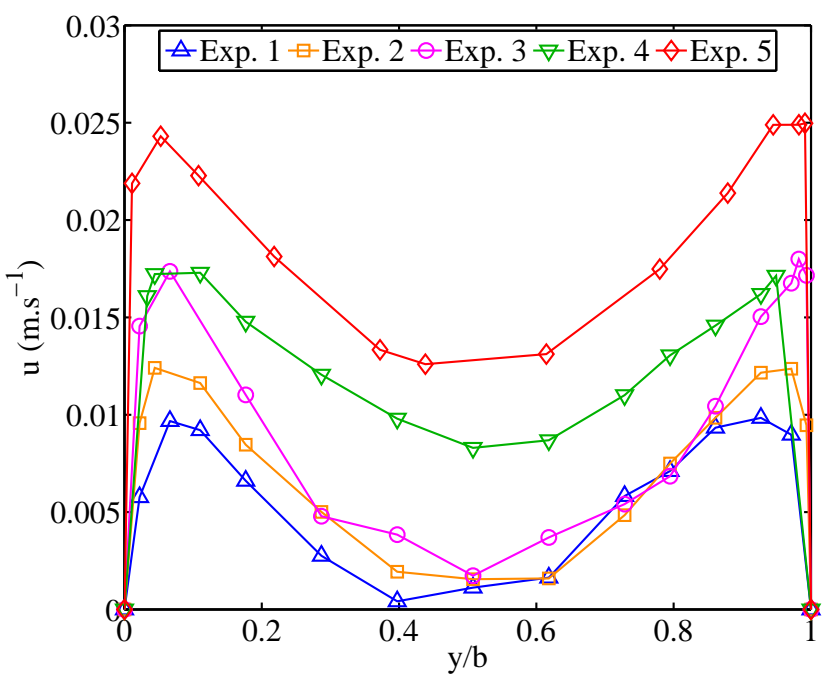

Figure 12: Mean vertical velocity in the channel mid-plane $(z / l=0.5)$ at the outlet $(x / H=0.90)$ versus the dimensionless distance from the left wall. Average velocities are calculated on 25-30 min. 


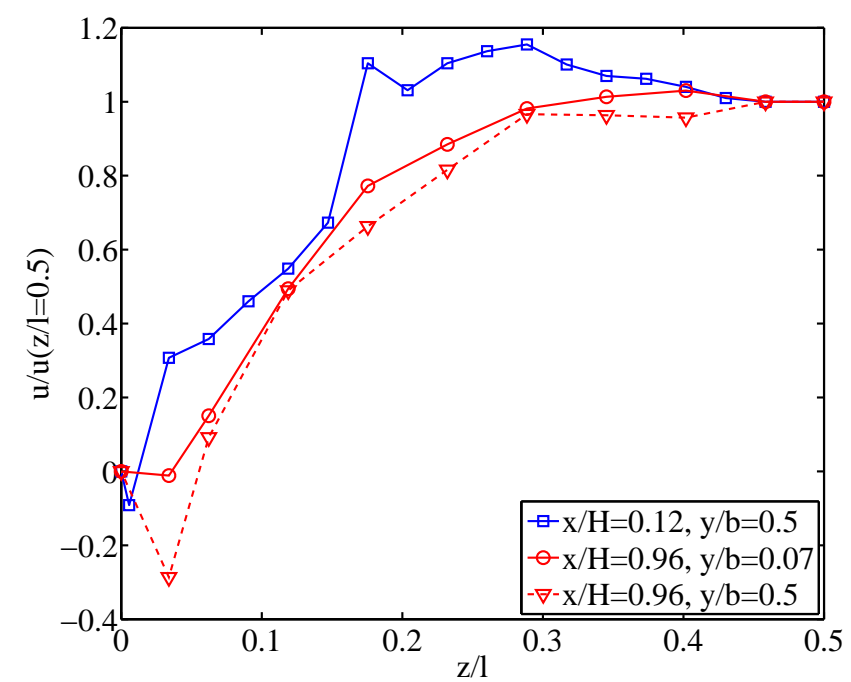

Figure 13: Mean velocity profile along $z$ axis at the channel inlet $(x / H=0.12)$ and outlet $(x / H=0.96)$.

$(x / H=0.12)$ and two measurements are done at the outlet $(x / H=0.96)$. The two measurements at the outlet show that $f_{\mathrm{c}}$ is weakly dependant on $y$. The three profiles are flat at the channel centre, $u=u(z / l=0.5)$ between $z / l=0.35$ and $z / l=0.5$, which means that the flow can be estimated 2D in the centre. After this plateau, the velocity decreases up to the lateral edge of the channel $(z=0)$ where the velocity is zero. Due to the thickening of the velocity boundary layer on the lateral wall, the decrease is more pronounced at the outlet than at the inlet. The slight increase on the inlet profile at $z / l=0.2$ is not significiant and could be due to measurement uncertainty.

Because the corrective function evolves slightly along the channel, it is assumed to be linear-dependent with respect to x. Therefore eqs. 4 and 5 lead to:

$$
\dot{M}(x)=\rho \int_{0}^{l} f_{\mathrm{c}}(x, z) \cdot d z \int_{0}^{b} u(x, y, z / l=0.5) \cdot d y .
$$

By using the measurements shown on fig. 13, the integral can be calculated at the entry and the exit, which leads to

$$
D(x)=\frac{1}{l} \int_{0}^{l} f_{\mathrm{c}}(x, z) \cdot d z=-0.173 \frac{x}{H}+0.875 .
$$

Table 2 shows the mass flow rates for each experiment, calculated at the inlet and at the outlet. The very good matching between inlet and outlet flow rates for 4 of these experiments validates the method used to account for $3 \mathrm{D}$ aspect of the flow. However, the discrepancy obtained for experiment 2 remains unexplained and could be attributed to the difficulty to do measurement at the channel entry.

\subsection{Energy balance}

The energy budget implies that the power injected by the 24 heaters is equal to the power transported by the flow at the channel outlet. Energy balance leads to:

$$
\dot{q}_{\mathrm{w}} S=\frac{1}{\tau} \int_{0}^{l} \int_{0}^{b} \int_{0}^{\tau} \rho c_{\mathrm{p}} u^{*}\left(T^{*}-T_{\mathrm{in}}^{*}\right) \cdot d t \cdot d y \cdot d z
$$

\begin{tabular}{c|ccc} 
& $\begin{array}{c}\dot{M}_{\text {in }} \\
\text { Exp. }\end{array}$ & $\begin{array}{c}\dot{M}_{\text {out }} \\
10^{-1}\left(\mathrm{~kg} . \mathrm{s}^{-1}\right)\end{array}$ & $\begin{array}{c}\frac{\Delta \dot{M}}{\dot{M}_{\text {out }}} \\
\left(0^{-1}\left(\mathrm{~kg} . \mathrm{s}^{-1}\right)\right.\end{array}$ \\
\hline 1 & 1.52 & 1.55 & +2 \\
2 & 2.45 & 1.98 & -23 \\
3 & 2.31 & 2.52 & +8 \\
4 & 3.78 & 3.81 & $<1$ \\
5 & 5.28 & 5.56 & +5
\end{tabular}

Table 2: Values of the mass flow rate calculated with corrective coefficient $D$ to take into account the $3 \mathrm{D}$ nature of the flow $(\dot{M}$, see eq. 7$)$.

where $u^{*}$ and $T^{*}$ are the instantaneous values of the velocity and temperature; $l$ is the channel depth along the $z$ direction, $S$ is the heated surface and $\tau$ is the duration used for calculating the averages. The Reynolds decomposition $u^{*}=u+u^{\prime}$ and $\Delta T^{*}=T^{*}-T_{\text {in }}^{*}=\Delta T+\theta^{\prime}$, leads to:

$$
\dot{q}_{\mathrm{w}} S=\dot{Q}_{\mathrm{f}}+\dot{Q}_{\mathrm{f}}^{\prime}
$$

with,

$$
\begin{aligned}
& \dot{Q}_{\mathrm{f}}=\int_{0}^{l} \int_{0}^{b} \rho c_{\mathrm{p}} u \Delta T \cdot d y \cdot d z \\
& \dot{Q}_{\mathrm{f}}^{\prime}=\int_{0}^{l} \int_{0}^{b} \rho c_{\mathrm{p}}<u^{\prime} \theta^{\prime}>\cdot d y \cdot d z
\end{aligned}
$$

and,

$$
<u^{\prime} \theta^{\prime}>=\frac{1}{\tau} \int_{0}^{\tau} u^{\prime} \theta^{\prime} . d t .
$$

$\dot{Q}_{\mathrm{f}}$ is the power transported by the mean flow and $\dot{Q}_{\mathrm{f}}^{\prime}$ is the power due to fluctuating quantities.

To account for the 3D nature of the flow, $\dot{Q}_{\mathrm{f}}$ is calculated using the same corrective function as the one used to estimate the mass flow rate. Because temperature measurements can not be performed close to the right wall, the integral is only calculated on the left half channel assuming a symmetrical flow:

$$
\dot{Q}_{\mathrm{f}} \simeq 2 \rho l D(x / H=0.96) c_{\mathrm{p}} \int_{0}^{0.5 b} u \Delta T . d y .
$$

The error introduced by assuming a symmetrical flow is estimated with the difference between the flow rate calculated with the whole profile and with the left half profile (see fig. 12). This difference is $12 \%$ for experiment 1 and less or equal to $5 \%$ for the 3 others. Therefore the accuracy on the calculation of the power transported by the mean flow is estimated to $\pm 5 \%$.

Table 3 presents the value of the injected power $\dot{q}_{\mathrm{w}} S$ and the value of the power transported by the mean flow calculated for experiments 1, 3, 4 and 5 (there is no temperature profile for experiment 2). The power calculation for experiment 1 overestimates the power input which may be due to uncertainties at very low power input. The power injected in the channel can be concluded to be entirely transported by the mean flow. For the three other experiments, the calculated power is smaller than the power input, as expected. The difference is an estimation of 


\begin{tabular}{c|ccc} 
Experiment & $\begin{array}{c}\dot{Q}_{\mathrm{w}} \\
(\mathrm{W})\end{array}$ & $\begin{array}{c}\dot{Q}_{\mathrm{f}} \\
(\mathrm{W})\end{array}$ & $\begin{array}{c}\dot{Q}_{\mathrm{f}}^{\prime} \\
(\%)\end{array}$ \\
\hline 1 & 44 & 50 & -12 \\
3 & 175 & 132 & +25 \\
4 & 263 & 163 & +38 \\
5 & 530 & 357 & +33
\end{tabular}

Table 3: Values of the power input and the power calculated from the outlet profiles for 4 experiments.

the part of the convective heat transfer due to the fluctuations. This fluctuating part is much more important for experiment 4 and 5 when it represents more than a third of the total power. This result is related to a change in the flow behaviour (see next section).

\subsection{Analysis and discussion}

Dimensionless numbers are defined as:

- Modified Rayleigh number:

$$
R a_{\mathrm{b}}^{*}=\frac{g \beta \dot{q}_{\mathrm{w}} b^{5}}{v k \alpha H}
$$

- Reynolds number based on channel width:

$$
R e=\frac{u_{\mathrm{b}} b}{v}=\frac{D(x)}{v} \int_{0}^{b} u . d y
$$

- Nusselt number based on channel width:

$$
N u_{\mathrm{b}}=\frac{\dot{q}_{\mathrm{w}} b}{k \Delta T_{\mathrm{H}}} \text {. }
$$

The Reynolds number is calculated as the mass flow rate (see table 2) by using the corrective coefficient $D$ to take into account the 3D nature of the flow. The Nusselt number is based on the difference between the mean wall temperature and the inlet temperature $\left(\Delta T_{\mathrm{H}}=\frac{1}{H} \int_{0}^{H}\left(T_{\mathrm{w}}-T_{\text {in }}\right) \cdot d x\right)$.

Figures 14 and 15 show the Reynolds number and the Nusselt number respectively from the 5 experiments versus the modified Rayleigh number. Reynolds number are calculated at the inlet and the outlet of the channel. On figure 15, correlation from the litterature were added for comparison. These figures exhibit that the first three experiments (exp. 1-3) seem to follow a power law that is different from the one followed by the last two ones (exp 4-5). A straight line is plotted on figure 14 to emphasis the difference between experiments 1-3 and 4-5.

To explore this problem, the velocity profiles at the exit are scaled to merge their maxima. They are plotted on figure 16. Even with an uncertainty on the mean velocity values $\left( \pm 2 \mathrm{~mm} \cdot \mathrm{s}^{-1}\right)$, a change in the velocity profiles can be seen between experiments 3 and 4 . Indeed, the velocity at the centre of the channel is almost proportional to the maximum value, with a coefficient around 0.15 for the first three experiments.

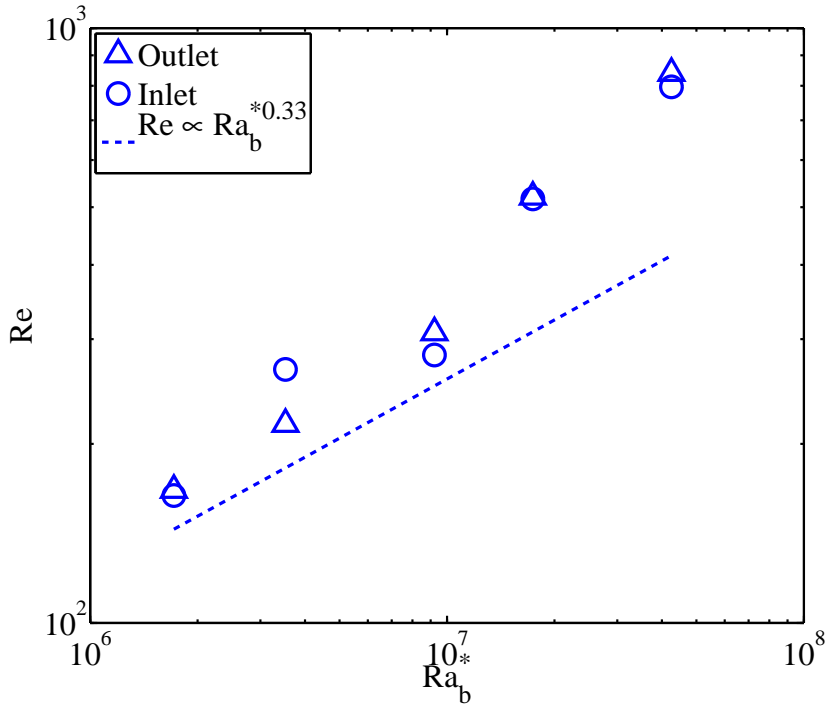

Figure 14: Reynolds number versus modified Rayleigh number for the five experiments, caculated at the channel outlet (traingles) and at the inlet (rounds).

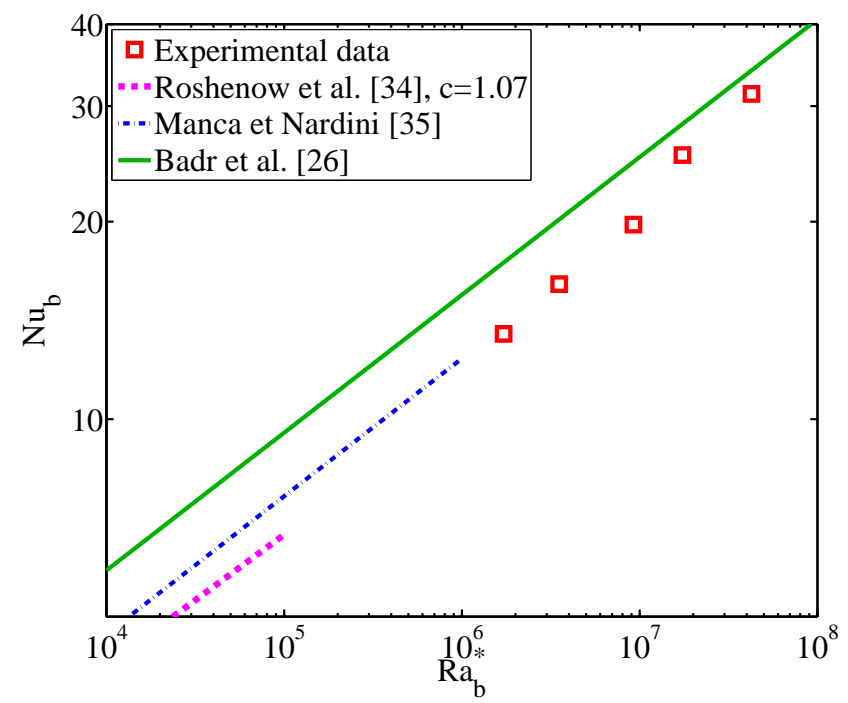

Figure 15: Nusselt number based on channel width versus modified Rayleigh number for the five experiments. The experimental results are compared to 3 correlations found in the literature ([34], [35] and [26]). 


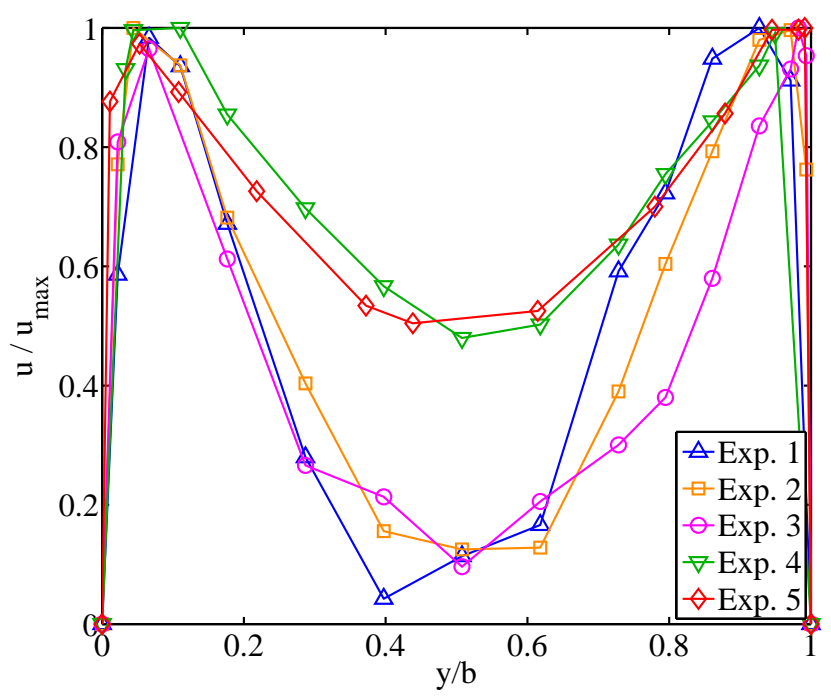

Figure 16: Mean dimensionless velocity profile at the channel outlet $(x / H=$ $0.90)$.

This coefficient of proportionality increased to 0.55 for the two last experiments. It is also illustrated by figure 17 which shows the difference $\Delta u$ between the maximum velocity and the midchannel velocity measured at the exit of the channel for the five experiments. Because the location of the maximum and the minimum of the velocity profiles remains almost the same for all the experiments, $\Delta u$ can be seen as an estimation of the global shear at the channel outlet (up to a constant multiplier).

To find a physical meaning for this change, the profiles of the root mean square of the fluctuations of velocity and temperature at the channel outlet are plotted in figure 18, 19 and 20. Figure 18 displays the root mean square of the vertical velocity fluctuations made non dimensional by the velocity difference $\Delta u$ for the 5 experiments. For experiments 1 to 3 , the root mean square is proportional to the velocity difference with a coefficient around 0.15 . The shape of the profile of experiment 1 which seems to increase with $y / b$ is not relevant due to the uncertainty which is high when the mean velocity is low. Experiments 4 and 5 show the same behaviour but with a coefficient around 0.5 . Similar observations can be made on the root mean square of the horizontal velocity fluctuations plotted on figure 19 where the root mean square is also made non dimensional by $\Delta u$. Measurements can not be performed close to the wall because one of the laser beams was impeded by the box. For experiments 1 and 2 , the ratio between the root mean square and the velocity difference $(\Delta u)$ remains very low. This ratio increases slightly for experiment 3 (around 0.08), and becomes three times higher for experiments 4 and $5(\sim 0.25)$. Figure 20 presents, for experiments 1 and 3 to 5 , the root mean square of the temperature fluctuations in the channel, with regard to inlet temperature, divided by the mean temperature difference between the wall and the inlet. The four curves have a similar behaviour, temperature fluctuations increase with the temperature difference between the wall and the inlet without any detectable change between experiments.

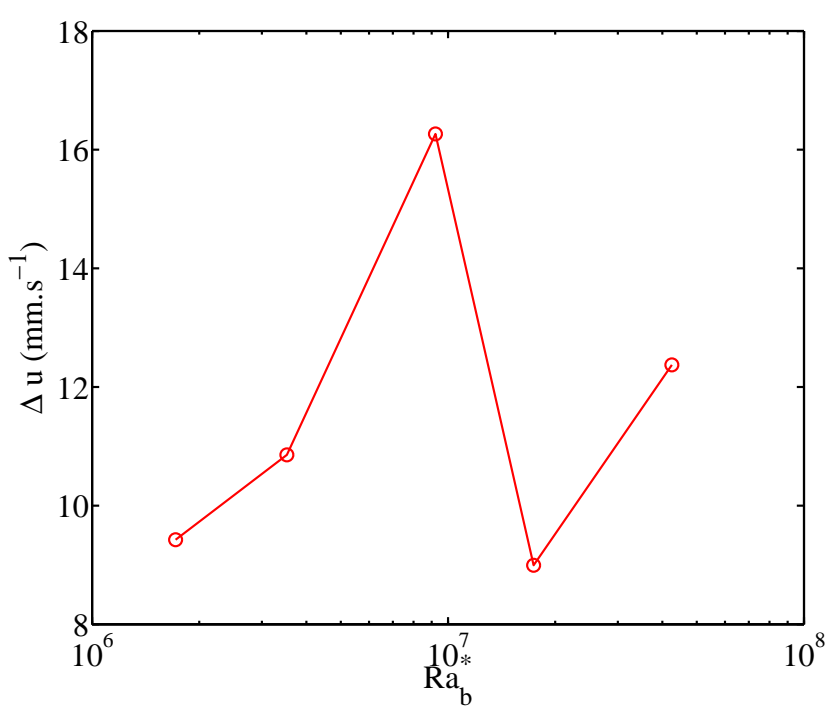

Figure 17: Mean velocity difference between maximum (close to the wall) and minimum (at channel centre) on outlet velocity profiles versus modified Rayleigh number $\left(R a_{\mathrm{b}}^{*}\right)$.

A change in the flow behaviour is suggested to explain the changes observed between the first three and the last two experiments. Indeed, for experiments 1 to 3 , an increase of the modified Rayleigh number leads to an increase of the mean velocity difference $\Delta u$ (see fig. 17) which corresponds to an increase of the global shear at the channel outlet. The level of the global shear drives the level of the velocity fluctuations as shown on figures 18 and 19. The growth of the velocity fluctuations increases the mixing between the fast fluid layer close to the walls and the slow layer at the centre of the channel. So beyond a limit, the mixing becomes sufficient enough to reduce the total shear as shown from experiments 4 and 5. This more efficient mixing is shown by the increase of the Nusselt number on figure 15. Figure 14 suggests that this higher thermal exchange comes with a different evolution of the Reynolds number against the Rayleigh number, but this point has to be studied in more details. Concerning the temperature fluctuations, no special behaviour is noticed between the experiments. Following our explanations, we may expect a jump in the temperature fluctuations between experiments 3 and 4 . But temperature difference with respect to the inlet temperature remains small and located in a thin thermal bondary layer (see fig. 8) and the ratio between the temperature fluctuations and the mean temperature difference remains lower than 0.2 (see fig. 20). Therefore, a change of behaviour is difficult to detect on the temperature measurements. Nevertheless, figure 8 shows a small increase of the bulk temperature for experiment 5 which stengthens the idea of a more efficient mixing inside the channel. Moreover, the mixing impact is also observed on the estimation of the heat rate transported by the fluctuating flow (see table 3 ). This heat rate increases from 25 to $35 \%$ between experiments 3 and 4 due to a better mixing between the fast and hot fluid layer and the slow and cold fluid at the centre. For now, the modified Rayleigh number characteristic of this change is estimated around $10^{7}$, but further investigations are needed to specify this threshold. 


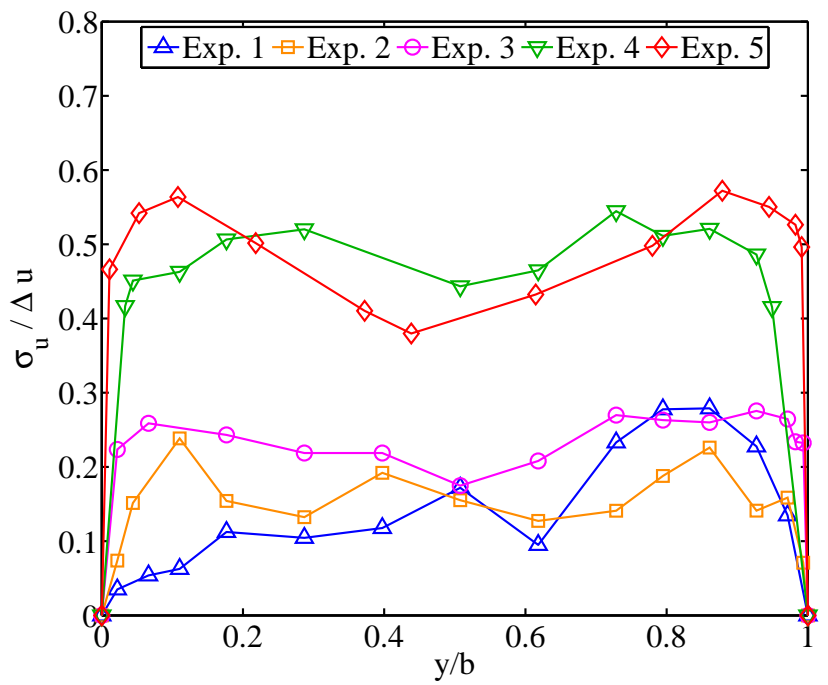

Figure 18: Root mean square profiles of the vertical velocity at the channel outlet for the 5 experiments. The Root mean square is divided by the velocity difference at the outlet (see fig. 17).

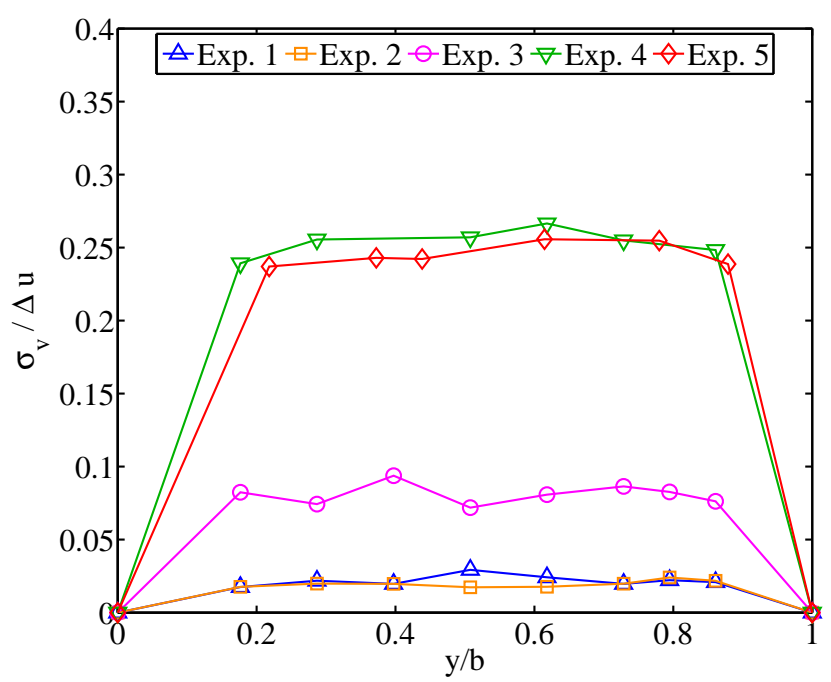

Figure 19: Root mean square profiles of the horizontal velocity at the channel outlet for the 5 experiments. The Root mean square is divided by the velocity difference at the outlet (see fig. 17).

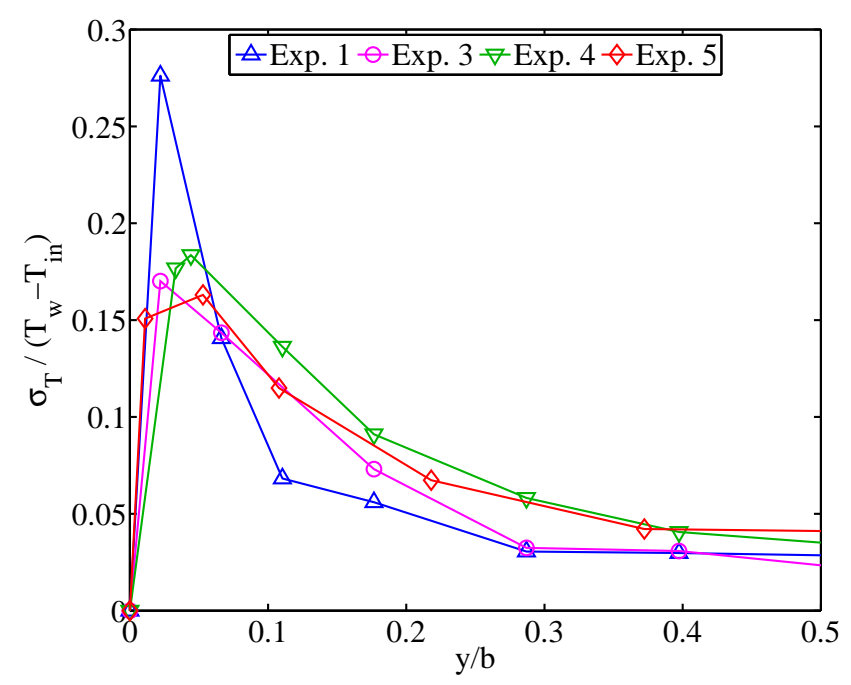

Figure 20: Root mean square profiles of the temperature at the channel outlet for the 5 experiments. The Root mean square is divided by the difference between the mean wall temperature at the outlet and the mean temperature at the inlet.

\section{Conclusion}

An original experimental apparatus was developed to study the natural convection of a water flow in a vertical channel. The boundary conditions on the heated channel walls were isoflux conditions and the external channel temperature was regulated. The test bench and its instrumentation was described and characterised. The temperature profiles in a heated wall were shown for five different configurations (different isoflux conditions) as were the velocity and temperature profiles in the channel. The temperature measurements were accurate even in the left thermal boundary layer (wall temperature gradiant is well approached), but improvements must be made close to the right wall. Measurements of the mean velocity were done by accounting for the high level of fluctuations that required long measurements. Moreover, 3D aspects were investigated and taken into account for the flow measurement that is obtained with a good accuracy.

The main result of this study is the observation of a change in the flow behaviour that occurs for a modified Rayleigh number around $10^{7}$. This change is attributed to a more efficient mixing between the fast layer close to the wall and the slow layer at the centre of the channel. This increase is clearly seen on the velocity fluctuations and it is strengthened by the estimation of the turbulent heat flux at the channel outlet that is higher for the higher Rayleigh numbers. This change is also observed on the correlations of the Nusselt and the Reynolds numbers as a function of the modified Rayleigh number. This exibits a discontinuity with respect to a classical power law.

Study of the coupling between the dynamic of the flow and the heat transfer has to be improved. Indeed the strong point of this apparatus is that it allows velocity and temperature measurement at the same time and at very close location. Therefore future studies will address the problem of synchronized velocity and temperature measurements. Lastly, the experimental device was improved to allow horizontal velocity measurements close 
to the wall.

This research was funded by the French National Research Agency in the framework of the project $n^{\circ}$ ANR-08-JCJC0018-01 and the National Agency of Energy Managment ADEME-0705C0076.

[1] B. J. Brinkworth, Estimation of flow and heat transfer for the design of pv cooling ducts, Solar Energy 69 (2000) 413-420.

[2] B. Brinkworth, Optimum depth for pv cooling ducts, Solar Energy 80 (2006) 1131-1134.

[3] B. Brinkworth, M. Sandberg, Design procedure for cooling ducts to minimise efficiency loss due to temperature rise in pv arrays, Solar Energy 80 (2006) 89-103.

[4] A. K. da Silva, G. Lorenzini, A. Bejan, Distribution of heat sources in vertical open channels with natural convection, Int. J. Heat Mass Transfer 48 (2005) 1462-1469.

[5] H. Bhowmik, K. W. Tou, Experimental study of transient natural convection heat transfer from simulated electronic chips, Experimental Thermal and Fluid Science 29 (2005) 485-492.

[6] O. Manca, M. Musto, V. Naso, Experimental analysis of asymmetrical isoflux channel-chimney systems, International Journal of Thermal Sciences 42 (2003) 837-846.

[7] W. Elenbaas, Heat dissipation of parallel plates by free convection, Physica IX 39 (1942) 1-28.

[8] J. R. Bodoia, J. F. Osterle, The delopment of free convection between heated vertical plates, Journal of Heat Transfer 84 (1962) 40-44.

[9] W. Aung, Fully developed laminar free convection between vertical plates heated asymmetrically, Int. J. Heat Mass Transfer 15 (1972) 1577-1580.

[10] E. M. Sparrow, J. L. Gregg, Laminar free convection from a vertical plate with uniform surface heat flux, Transaction of the ASME 78 (1956) 435440.

[11] R. A. Wirtz, R. J. Stutzman, Experiments on free convection between vertical plates with symmetric heating, Journal of Heat Transfer 104 (1982) 501-507.

[12] W. Aung, L. S. Fletcher, V. Sernas, Developing laminar free convection between vertical flat plates with asymmetric heating, Int. J. Heat Mass Transfer 15 (1972) 2293-2308.

[13] A.-M. Dalbert, F. Penot, J.-L. Peube, Convection naturelle laminaire dans un canal vertical chauffãl' Ãă flux constant, Int. J. Heat Mass Transfer 24 (1981) 1463-1473.

[14] E. M. Sparrow, P. A. Bahrami, Experiments on natural convection from vertical parallel plates with either open or closed edges, Journal of Heat Transfer 102 (1980) 221-227.

[15] A. Bar-Cohen, W. M. Rohsenow, Thermally optimum spacing of vertical, natural convection cooled, parallel plates, Journal of Heat Transfer 106 (1984) 116-123.

[16] S. W. Churchill, R. Usagi, A general expression for the correlation of rates of transfer and other phenomena, AIChE Journal 18 (1972) 1121-1128.

[17] C.-O. Olsson, Prediction of nusselt number and flow rate of buoyancy driven flow between vertical parallel plates, Journal of Heat Transfer 126 (2004) 97-104.

[18] B. W. Webb, D. P. Hill, High rayleigh number laminar natural convection in an asymmetrically heated vertical channel, Journal of Heat Transfer 111 (1989) 649-656.

[19] T. R. Borgers, H. Akbari, Free convective turbulent flow within the trombe wall channel, Solar Energy 33 (1984) 253-264.

[20] M. Miyamoto, Y. Katoh, J. Kurima, H. Sasaki, Turbulent free convection heat transfer from vertical parallel plates, in: Hemisphere (Ed.), International Heat Transfer Conference, volume 4, pp. 1593-1598.

[21] A. G. Fedorov, R. Viskanta, Turbulent natural convection heat transfer in an asymmetrically heated, vertical parallel-plate channel, Int. J. Heat Mass Transfer 40 (1997) 1849-3860.

[22] B. Moshfegh, M. Sandberg, Flow and heat transfer in the air gap behind photovoltaic panels, Renewable and Sustainable Energy Reviews 2 (1998) 287-301.

[23] X. Cheng, U. Müller, Turbulent natural convection coupled with thermal radiation in large vertical channels with asymmetric heating, Int. J. Heat Mass Transfer 41 (1998) 1681-1692.

[24] M. A. Habib, S. A. M. Said, S. A. Ahmed, A. Asghar, Velocity characteristics of turbulent natural convection in symmetrically and asymmetri- cally heated vertical channels, Experimental Thermal and Fluid Science 26 (2002) 77-87.

[25] T. F. Ayinde, S. A. M. Said, M. A. Habib, Experimental investigation of turbulent natural convection flow in a channel, Heat Mass Transfer 42 (2006) 169-177.

[26] H. M. Badr, M. Habib, S. Anwar, R. Ben-Mansour, S. A. M. Said, Turbulent natural convection in vertical parallel-plate channels, Heat Mass Transfer 43 (2006) 73-84.

[27] S. Giroux-Julien, C. Ménézo, J. Vareilles, H. Pabiou, M. Fossa, E. Leonardi, Natural convection in nonuniformily heated channel investigation - application to photovoltaic façades, Computationnal Thermal Sciences 1 (2009) 231-258.

[28] B. Zamora, A. Kaiser, Optimum wall-to-wall spacing in solar chimney shaped channels in natural convection by numerical investigation, Applied Thermal Engineering 29 (2009) 762-769.

[29] T. Yilmaz, S. M. Fraser, Turbulent natural convection in a vertical parallel-plate channel with asymmetric heating, Int. J. Heat Mass Transfer 50 (2007) 2612-2623.

[30] E. M. Sparrow, G. M. Chrysler, L. F. Azevedo, Observed flow reversals and measured-predicted nusselt numbers for natural convection in a onesided heated vertical channel, Journal of Heat Transfer 106 (1984) 325332.

[31] E. Sparrow, L. Azevedo, Vertical-channel natural convection spanning between the fully-developed limit and the single-plate boundary-layer limit, Int. J. Heat Mass Transfer 28 (1985) 1847-1857.

[32] H. Bhowmik, C. P. Tso, K. W. Tou, F. L. Tan, Convection heat transfer from discrete heat sources in a liquid cooled rectangular channel, Applied Thermal Engineering 25 (2005) 2532-2542.

[33] D. D. Gray, A. Giorgini, The validity of the boussinesq approximation for liquids and gases, Int. J. Heat Mass Transfer 19 (1976) 545551.

[34] W. M. Rohsenow, J. P. Hartnett, Y. I. Cho, Handbook of Heat Transfer, Mc Graw-Hill,New York, 1998.

[35] O. Manca, S. Nardini, Composite correlations for air natural convection in tilted channels, HEAT TRANSFER ENGINEERING 20 (1999) 64-72.

[36] H. Tennekes, J. L. Lumley, A First Course in Turbulence, M I T Press, 1972. 